\title{
Chaos, Complexity, and Contingency Theories: A Comparative Analysis and Application to the 21st Century Organization
}

\author{
Franklin M. Lartey ${ }^{1}$ \\ ${ }^{1}$ Cox Communications, 6305 Peachtree Dunwoody Road, Atlanta, GA 30328, USA \\ Correspondence: Franklin M. Lartey, Cox Communications, 6305 Peachtree Dunwoody Road, Atlanta, GA 30328, \\ USA
}

Received: June 18, 2020 Accepted: June 25, 2020 Online Published: June 29, 2020

doi:10.5430/jbar.v9n1p44 URL: https://doi.org/10.5430/jbar.v9n1p44

\begin{abstract}
Organizations in the $21^{\text {st }}$ century deal with constant changes such as globalization, technological evolutions, regulatory changes, competition, and other unexpected events, among others. These challenges can be viewed and addressed through the lenses of contemporary theories. This paper selected three contemporary theories namely chaos, complexity, and contingency theories, and presented their foundations and characteristics by comparing and contrasting their key concepts. These concepts include nonlinearity, feedback, bifurcation, strange attractors, fractals, and self-organization for chaos theory; nonlinearity, dynamism, feedback, self-organization, emergence, and adaptability for complexity theory; and adaptation, equifinality, effectiveness, and congruency for contingency theory. Examples of studies and organizational applications of these theories were provided, and implications for scholars and organizational leaders were discussed. By explaining notions such as how the capacity of a system could be greater than the sum of the capacities of its subunits, this paper can act as a starting point for anyone seeking to understand the three theories or use them for research or organizational purposes.
\end{abstract}

Keywords: chaos theory, complexity theory, contingency theory, chaos, complexity, contingency, fractal, bifurcation, strange attractor, self-organization, nonlinearity, feedback

\section{Introduction}

With constant changes such as technological evolutions and globalization affecting organizations and their environments, management theories need to adapt and address emerging challenges. In today's organizational environments, contemporary management theories take in consideration these rapid changes, helping to interpret and explain the impact of the changes on organizations (Porth \& McCall, 2001). While literature identifies many contemporary management theories such as contingency theory, open systems theory, resource theory, and team building theory just to name a few, complexity theory and chaos theory still seem difficult to understand and implement in contemporary organizations. The purpose of this article is to present these two theories (chaos and complexity theories) comparatively to the contingency theory in a way that is easy to understand and apply.

To achieve the above stated goal, this article will compare and contrast the three theories (chaos, complexity, and contingency theories) using a block approach combined with the point-to-point method. To that effect, it will first provide a detailed presentation of chaos theory. Next, a presentation of the complexity theory will be done, comparing and contrasting its key concepts with those of the chaos theory already presented. Finally, a presentation of the contingency theory will be done in comparison and contrast to both the chaos and complexity theories. To put everything into perspective, this article will also discuss specific studies conducted on these theories and demonstrate the implications of the theories for researchers and organizational leaders.

\section{Chaos Theory}

\subsection{Presentation}

Chaos theory originated from the work of the French mathematician Henri Poincaré. In 1903, Poincaré discovered that simple systems such as the earth orbiting around the sun had an unpredictable behavior (Oestreicher, 2007; Thietart \& Forgues, 1995). It is only later in the 1960s that his findings regained interest in the scientific arena with the work of Edward Norton Lorenz, an American mathematician and meteorologist. While modeling the weather on a computer, Lorenz discovered that a change in the scale of a millionth of a decimal point could completely change 
the outcome of the weather prediction. In other words, a butterfly flapping its wings in Brazil could result in a thunderstorm in Texas two years later (Oestreicher, 2007). This was coined the butterfly effect, which depicts sensitivity to initial condition and constitutes the basis of chaos theory.

Chaos is not disorder; it represents unpredictability in an evolutionary system of order. Chaos theory studies dynamic systems characterized by non-linearity, complex interactions, and dynamical evolution over time (Levy, 1994; Lorenz, 1995). It suggests that a small change in the initial condition of a non-linear dynamic system can result in unexpected outcomes, making dynamic systems difficult to predict.

Industries are forms of chaotic systems. As explained by Levy (1994), industries evolve over time based on interactions among firms, governments, institutions, consumers, the environment, and other actors. Hence, predicting the impact of these interactions on a system is almost impossible because the same interaction can result in different outcomes depending on the specific industry and its initial state. Another well known example of a chaotic system is the weather system. In his book titled The Essence of Chaos, Lorenz (1995) explains that the weather system with its elements such as temperature, winds, humidity, clouds, and other parameters create a nonlinear dynamical system not subject to the laws of cause and effect. The weather system is indeed the system from which the chaos theory emanated, based on its susceptibility to initial conditions. Besides the two examples above, there are other chaotic systems around the world, some as small as a rock rolling down the hill, and others as large as the universe. All these systems have several characteristics in common as discussed in what follows.

\subsection{Key Constructs of Chaos Theory}

The literature on chaos theory suggests the existence of many key constructs. Six key constructs also referred-to as key features or central assumptions were identified in the literature and selected for this study. These key constructs are (1) nonlinearity; (2) feedback; (3) bifurcation; (4) strange attractors; (5) fractals; and (6) self-organization (Betchtold, 1997; Doherty \& Delener, 2001; Murphy, 1996). Other constructs exist but appear in very few publications, which is the reason why this study focuses on the six main concepts presented above.

\subsubsection{Nonlinearity}

Central to chaos theory is the principle of nonlinearity. A nonlinear system is a system in which the relationships between its variables are not linear or proportional (Thietart \& Forgues, 1995). This concept is opposed to that of the Newtonian reductionist principle suggesting that cause and effect have a linear relationship and the amplitude of the effect is proportional to that of the cause. As such, even minute changes in the initial state of the nonlinear system can result in catastrophic effects, thus the need for the system to control its evolution through feedback.

\subsubsection{Feedback}

Because systems are in a perpetual state of evolution and transformation in the chaos theory, they require feedbacks to maintain a sense of stability. Murphy (1996) posits that positive feedback helps chaotic systems evolve by introducing new patterns. Betchtold (1997) on the other hand adds that negative feedbacks help the systems maintain their stability. An analogy used by scholars is that of a sound system with the microphone placed in front of a speaker. In such configuration, the system's output from the speaker becomes its input, which reintroduces the sound distortion in the system and iteratively amplifies it. Similarly, each output in a chaotic system provides elements for a new outcome. With such a recursive process, there are possibilities of bifurcating to a different path thus changing the state of the system.

\subsubsection{Bifurcations}

In a chaotic system, bifurcation points can cause a sudden change in the system's direction, characteristics, and outcome. As explained by Gauthier (2009), bifurcation points are points within the system that are unstable, causing the system to dramatically change direction, structure, or character. Knowing these unstable points allows for the prediction of a bifurcation, but the outcome of the bifurcation or next state of the system is unpredictable. Nevertheless, chaotic systems still demonstrate repetitive abilities, allowing researchers to identify strange patterns.

\subsubsection{Strange attractors}

Even though dynamic systems are unpredictable, they still have boundaries within which they operate their transformations, thus creating patterns known as attractors. As explained by Murphy (1996), strange attractors with different shapes such as doughnuts, butterfly wings, and other forms characterize chaotic systems. These strange attractors define the boundaries of dynamic systems as these systems progress toward chaos due to their continuous growth. Like any element in a system, strange attractors are identifiable and measurable using fractals. 


\subsubsection{Fractals}

The basic unit of identification of a strange attractor is the fractal. According to Doherty and Delener (2001), strange attractors have a fractal dimension. Fractals are objects that infinitely repeat their shape within their structure, looking the same independently of their form or magnification level. Fractals can be magnified forever and continue containing other fractals of the same shape, form and characteristics. A well-known fractal based on a simple mathematical concept is the Mandelbrot set (Lorenz, 1995). The confinement of strange attractors on a limited region with the infinite nature of fractals make it impossible to predict the long-term aspect of a system due to the unlimited potential paths created by the fractals. The infinite replication of fractals within the system presents the opportunity for self-organization.

\subsubsection{Self-Organization}

Self-organization can occur only after a change in the system. It is the capacity to communicate a change within the system in order to allow all parts to react to the change and generate a new inner state or form. Self-organization is inherent to chaotic systems and does not require external intervention (Murphy, 1996). This characteristic explains the continuous evolution of the system toward a bifurcation point and chaotic state.

\section{Complexity Theory}

\subsection{Presentation}

The second theory studied in this paper is the complexity theory. Complexity theory is a technique that simplifies the explanation and analysis of complex systems. Complex systems are nonlinear dynamic systems made of many interacting components or subunits just as in the case of chaos theory (Manson, 2001; Rickles, Hawe, \& Shiell, 2007; Sanger \& Giddings, 2012). Contrarily to simple systems that have few parts interacting based on simple laws, complex systems have many independent and interacting parts performing together a complex function that no part can singularly perform.

Researchers can apply both complexity theory and chaos theory in different ways based on the situation. In social sciences, researchers can apply them metaphorically or conceptually, while in physical sciences researchers apply them mathematically (Sanger \& Giddings, 2012). There are many examples of complex systems around the world and in everyday life. These include multinational organizations, ecosystems such as rainforests, and integrated software on network distributed environments (Burnes, 2005; Hurlburt, 2013; Manson, 2001). The role of complexity theory in these examples consists of simplifying the complexity of the systems. Due to the variety of types of complex systems, complexity theory has a number of core characteristics, some of which are comparable to the characteristics of chaos theory.

\subsection{Key Characteristics of Complexity Theory}

Just like chaos theory, complexity theory exhibits many different characteristics. Some of these key concepts include nonlinearity, dynamism, feedback, self-organization, emergence, and adaptability. Many of these characteristics are analogous to those of chaotic systems, but there are differences that make the two systems apart from each other.

\subsubsection{Nonlinearity, dynamism, and feedback}

Just like chaotic systems, complex systems are nonlinear, dynamic, and require feedback. As such, they are also subject to the sensitivity of their initial condition, which makes the evolution of the systems difficult to predict (Schneider \& Somers, 2006). This principle of sensitivity to initial condition is what appeared earlier in this study under the label of the butterfly effect. Complex systems share other characteristics with chaotic systems, one of which is self-organization.

\subsubsection{Self-Organization}

Like chaotic systems, the self-organizing abilities of their subunits characterize complex systems. As explained by David Ng (2013), self-organization is at the core of complexity theory and suggests a spontaneous appearance of new global patterns from local subunit interactions. This same behavior appears in chaos theory and explains the dynamic and evolutionary nature of the systems. In addition to self-organization in complex systems, there is the notion of emergence.

\subsubsection{Emergence}

While chaos and complexity are closely related, they are still perfectly distinct. One characteristic of complex systems not found in chaotic systems is that of emergence. The emergent property of a complex system suggests that interactions between its subcomponents generate new properties that are not limited to the subcomponents (Rickles, 
Hawe, \& Shiell, 2007; Uhl-Bien, Marion, \& McKelvey, 2007). Manson (2001) summarizes this property by stating that the total capacity of a complex system is greater than the sum of the capacities of its subcomponents. Emergence materializes as the development of new intelligence or patterns from the bottom up within a complex system. In other words, the micro level makes decisions and propagates them at the macro level.

\subsubsection{Other Key Differences}

Besides emergence, one notable difference between complex and chaotic systems resides in the number of elements constituting their subunits. Rickles et al., (2007) posit that complex systems are more coherent than chaotic systems. In addition, uncertainty arises differently in both systems. In chaotic systems, uncertainty is due to the inability of knowing the initial condition of the system. In contrast, uncertainty is inherent to complex systems due to the notion of emergence. Complexity theory deals with the emergence of order in complex systems at the edge of chaos (Burnes, 2005). The edge of chaos represents a point along the boundary between determinism and randomness. At this point, the system is neither random nor deterministic. While chaos theory studies deterministic systems, complexity theory studies non-deterministic systems. As such, to understand social systems that are non-deterministic by essence, it is better to use complexity theory.

\section{Contingency Theory}

\subsection{Presentation}

The third theory analyzed in this article is contingency theory. It is an approach suggesting that the best solution to a problem depends on various factors such as the environment, goals, technology, and people involved. Contrary to classical theories that advocate one best way of doing things, contingency theory suggests that the best way depends on the environmental uncertainty and instability as well as other contingent factors (Tosi \& Slocum, 1984). Like chaos theory and complexity theory, contingency theory refutes the idea of single best way, suggesting that the best solution depends on the situation. While complexity and chaos theories refute the Newtonian reductionist idea of system linearity, contingency theory refutes the traditional idea of single managing principle and suggests the application of different management styles depending on the situation. Like many other organizational challenges, managing depends on the situation in which it is applied, and the notion of situational decision-making constitutes the basis of the contingent approach.

Contingency theory deals with the open systems view of the organization as a set of interdependent parts that constitute a whole, which in turn is interdependent with its environment. Indeed, contingency theory sees organizations as complex systems faced with uncertainty while being subjected to rational criterion at the same time (Thompson, 2003). Presented as such, contingency theory suggests the existence of a complex system with interdependent subunits similar to that of complexity theory. Like chaos theory and complexity theory, contingency theory has key concepts common to the various approaches of the theory.

\subsection{Key Constructs of Contingency Theory}

Contingency theory has key constructs that help identify relationships among variables. Some of these constructs include adaptation and equifinality as identified by Zeithaml, Varadarajan, and Zeithaml (1967), as well as effectiveness and congruency as identified by Tosi and Slocum (1984). These key notions are necessary in the implementation of empirical research on contingency theory.

\subsubsection{Adaptation}

The principle of adaptation in the contingency approach suggests that elements of a subsystem adapt with each other to the situation to preserve the overall system state. This concept is similar to that of self-organization seen in complex systems. As explained by Zeithaml et al. (1967), organizations create rational decision-making processes to face the complexity and uncertainty of various situations. This viewpoint is shared by Rejc (2004) who asserts that contingency theory helps identify aspects associated with specific circumstances to enable the system to adapt in case of any eventuality. By implementing the principles of the contingency approach, organizations create processes that encourage learning and problem solving, hence the capacity of self-organization similar to that of the complexity and chaos theories.

\subsubsection{Equifinality}

The concept of equifinality suggests that a system can reach the same final state from two different initial conditions and using different paths. As explained by Bokeno (2007), equifinality is a property of open systems expressing the possibility of achieving unexpected results from a single path or the expected results from different paths. This principle contrasts with that of sensibility to initial condition seen in both the complexity theory and chaos theory. 
Indeed, complexity and chaos theories emphasize on the importance of path dependence in nonlinear dynamic systems as explained by Warren, Franklin, and Streeter (1998), and suggests that any difference in the initial condition can result in dramatically different system states. This principle of chaos and complexity theories is contrary to the equifinality principle of the contingency theory.

\subsubsection{Effectiveness}

Effectiveness is a key notion of the contingency approach as it is essential in the adaptation and survival of the organization. Organizations can achieve effectiveness through many different ways such as efficiency, employee satisfaction due to pay, work-life balance, job security, and through social responsibility outcomes (Tosi \& Slocum, 1984; Zeithaml, Varadarajan, \& Zeithaml, 1967). Bokeno (2007) posits that effectiveness is a property of a linear system, suggesting that this property is not that of a complex system. Hence, this characteristic differentiates contingency theory from chaos and complexity theories.

\subsubsection{Congruency}

Congruency is a notion embedded in contingency theory and represents the fit of the organization in its environment. Tosi and Slocum (1984) assert that congruency is necessary in an organization's adaptability and survivability, but it is not adequate for profitability. Improving congruency, the authors posit, improves effectiveness. This notion does not exist in chaos and complexity theories because nonlinear dynamic systems exist within an environment without regard to a specific fit. As such, this is another notion that differentiates contingency theory from chaos and complexity theories.

\section{Specific Studies Conducted on Each Theory}

There exists a plethora of studies on each of the three theories presented in this article. For example, one application of chaos theory relates to the implementation of organizational change. As explained by Black (2008), chaos constructs have been helpful in situations where previous traditional efforts failed. Black illustrates this point with the case study of a community hospital that had difficulties maintaining quality standards and staying within its operating budgets. The management team of the hospital had unsuccessfully implemented prior changes. Initial analyses revealed that clinical services were in an equilibrium state, revolving around attractors such as inflexible structures and the culture of status quo. For that reason, the key to resolving the issues was a perturbation of the equilibrium, which would weaken the constraining attractors (Black, 2008). The transformation of the hospital based on the principles of chaos theory consisted of creating a shock to the current system.

First, the organization reduced management layers and hired new leaders from outside the organization. Second, it removed silos by allowing a matrix-based structure with shared directors in some departments. Third, the governing board of the hospital received training on the importance of change in the organization. Fourth and finally, the board hired a consultant to work on compliance. At this point of the transformation, the system would function and seek new attractors to get to a new state of equilibrium as suggested by the chaos theory.

Besides this study showing a concrete application of chaos theory in an organization, researchers conducted many other studies on chaos, complexity, and contingency theories. Some examples of studies include the application of chaos theory in predicting traffic on urban road networks (Adewumi, Kagamba, \& Alochukwu, 2016), and the use of complexity theory in organizational change (Burnes, 2005), in public administration management and policies (Meek, 2010; Teisman \& Klijn, 2008), and in software integration and testing (Hurlburt, 2013). Similarly, examples of research studies related to contingency theory include the work of Stonebraker and Afifi (2004) on the application of contingency theory to supply chain management; that of Rejc (2004) on the application of contingency theory on performance measurement; and even the work of Feldman (1976) on the application of contingency theory to socialization. As presented, researchers can use these theories in organizational, social, environmental, and scientific studies.

\section{Implications for Scholars and Organizational Leaders}

The development of the three contemporary theories presented in this study has many implications for both scholars and practitioners. As explained by Thietart and Forgues (1995), scholars and organizational leaders face challenges created by the limitations of traditional models, hence the need to implement contemporary theories that also have their advantages and limitations. This study will analyze the implications for scholars followed by the implications for organizational leaders.

\subsection{Implications for Scholars}

The notion of organizational complexity suggests the existence of a perpetual process of change within every 
subcomponent of the organization such as its members, structure, social system, and environment. Complexity theory can provide researchers with new methods of inquiry as they look at ways of enhancing research outcomes obtained through traditional methods (Swanson \& Zhang, 2011). For this reason, research on organizations needs to shift from the focus on individual components to the focus on the organization as a whole, due to the interactions among all subcomponents of a complex system. Other implications include the fields of application of the theories presented in this study.

Because complex systems exist in and around every individual, researchers can apply principles from chaos, complexity, and contingency theories in various fields. For example, Swanson and Zhang (2011) applied complexity theory to research on social entrepreneurship; Tenhiälä (2011) applied contingency theory to capacity planning; and Smith and Paquette (2010) applied chaos theory to creativity and knowledge management. These are fields that seem very different, but still share the same notions of contingency, complexity, and chaos. As such, researchers in any field of study can use these theories to understand existing systems and the challenges they face or present.

For a proper use of the theories discussed in this study, researchers need to understand their meaning and their use. In other words, researchers should work not only on applying the notions presented by the theories, but also on contributing to these theories as they are still evolving. Such contribution would suggest a good understanding of the theories and their ramifications, which would be propitious to a good application of the theories in any field of interest.

\subsection{Implications for Organizational Leaders}

A research conducted on the application of chaos theory to company strategy reveals some implications for organizational leaders. In a study of the application of chaos theory to supply chain management, Levy (1994) demonstrated how relatively small disruptions in the supply chain could result in very unpredictable outcomes for a company. The simulation of 100 months of a strategic decision to source from Singapore revealed that any instability in the supply chain would increase costs and expenses, disrupt production, and decrease revenue and satisfaction. That is exactly what happened around the world with the 2008 economic and financial crisis (Lartey, 2020) or the 2019 corona virus spread (COVID-19) that became a pandemic in 2020 (Remuzzi \& Remuzzi, 2020). Levy's study suggests that managers can use chaos theory as a framework to account for dynamic evolution and complex interactions that disrupt organizations. An implication for leaders is the knowledge that long-term planning and forecasting is unrealistic because dramatic events such as the COVID-19 pandemic are unpredictable. As a result, organizations need to be flexible and adaptive in order to survive in the increasingly competitive and unpredictable environment.

The complexity of organizations increases continuously due to evolving elements such as technology, globalization, needs, and competition, and managers need to address this growing complexity. To achieve their goals, managers should look at alternatives to traditional management deemed unfit for complex systems (Wilson, 2009). Because of the evolving nature of organizations and their environment, leaders need to make boundaries permeable within their firms, give up the idea of organizational stability, and allow ideas to flow bottom-up as specified by the emergence characteristic of complex systems (Manson, 2001; Rickles et al., 2007; Uhl-Bien et al., 2007). Understanding the theory behind complex systems, their unpredictable behaviors, and key characteristics will be useful in the implementation of practical notions appropriate for the management of organization complexity.

\section{Conclusion}

This article discussed three contemporary management theories namely chaos theory, complexity theory, and contingency theory, and explained their key constructs while comparing and contrasting them in a block and point-to-point structure. The article later presented some studies conducted on each of the theories, and finally analyzed the implications for scholars currently studying these concepts and for organizational leaders. The key concepts of chaos theory include nonlinearity, feedback, bifurcation, strange attractors, fractals, and self-organization. From chaos theory derived complexity theory with key constructs including nonlinearity, dynamism, feedback, self-organization, emergence, and adaptability. Contingency theory is an approach suggesting that the best decision depends on the situation. Its key constructs include adaptation, equifinality, effectiveness, and congruency. These theories are still in development and thus have advantages and limitations that researchers and organizational leaders should consider prior to their implementation.

\section{References}

Adewumi, A., Kagamba, J., \& Alochukwu, A. (2016) Application of Chaos Theory in the prediction of motorised traffic flows on urban networks. Mathematical Problems in Engineering. https://doi.org/10.1155/2016/5656734. 
Betchtold, B. L. (1997). Chaos theory as a model for strategy development. Empowerment in Organizations, 5(4), 193-201. https://doi.org/10.1108/14634449710195462

Black, J. (2008). Clinical transformation through the application of chaos theory. Nurse Leader, 6(6), 38-40. https://doi.org/10.1016/j.mnl.2007.11.017

Bokeno, M. (2007). Effective (linear) and emergent (nonlinear) mentoring: A practical context for practicing chaos. Development and Learning in Organizations, 21(5), 18-20. https://doi.org/10.1108/14777280710779445

Burnes, B. (2005). Complexity theories and organizational change. International Journal of Management Reviews, 7(2), 73-90. https://doi.org/10.1111/j.1468-2370.2005.00107.x

David Ng, F. S. (2013). Leadership learning through the lens of complexity theory. Human Systems Management, 32(1), 43-55. https://doi.org/10.3233/HSM-130783

Doherty, N., \& Delener, N. (2001). Chaos theory: Marketing \& management implications. Journal of Marketing Theory and Practice, 9(4), 66-75. https://doi.org/10.1080/10696679.2001.11501904

Feldman, D. C. (1976). A contingency theory of socialization. Administrative Science Quarterly, 21(3), 433-452. https://doi.org/10.2307/2391853

Gauthier, Y. (2009). The construction of chaos theory. Foundations of Science, 14(3), 153-165. https://doi.org/10.1007/s10699-008-9129-8

Hurlburt, G. F. (2013). Complexity theory - A new paradigm for software integration. IEEE Computer Society, 15(3), 26-31. https://doi.org/10.1109/MITP.2012.87

Lartey, F. M. (2020). Ethical challenges of complex products: Case of Goldman Sachs and the synthetic collateralized debt obligation. International Business Reserch, 13(6), 115-127. https://doi.org/https://doi.org/10.5539/ibr.v13n6p115. Retrieved from https://www.researchgate.net/profile/Franklin_Lartey/publication/341624526_Ethical_Challenges_of_ Complex_Products_Case_of_Goldman_Sachs_and_the_Synthetic_Collateralized_Debt_Obligations

Levy, D. (1994). Chaos theory and strategy: Theory, application, and managerial implications. Strategic Management Journal, 15, 167-178. https://doi.org/10.1002/smj.4250151011

Lorenz, E. (1995). The essence of chaos. London, United Kingdom: UCL Press Limited.

Manson, S. M. (2001). Simplifying complexity: A review of complexity theory. Geoforum, 32(3), 405-414. https://doi.org/10.1016/S0016-7185(00)00035-X

Meek, J. W. (2010). Complexity theory for public administration and policy. Emergence: Complexity \& Organization, 12(1), 1-4. Retrieved from https://www.researchgate.net/publication/264083014_Complexity_theory_ for_public_administration_and_policy

Murphy, P. (1996). Chaos theory as a model for managing issues and crisis. Public Relations Review, 22(2), 95-113. Retrieved from https://www.thefreelibrary.com/Chaos+theory+as+a+model+for+managing + issues + and + crises.-a018660770

Oestreicher, C. (2007). A history of chaos theory. Dialogues in Clinical Neuroscience, 9(3), 279-289. Retrieved from http://www.ncbi.nlm.nih.gov/pmc/articles/PMC3202497/pdf/DialoguesClinNeurosci-9-279.pdf

Porth, S. J., \& McCall, J. (2001). Contemporary management theories and Catholic social teaching: Similarities and differences. Review of Business, 22(3), 8-15. Retrieved from Gale Academic OneFile https://go.gale.com

Rejc, A. (2004). Toward contingency theory of performance measurement. Journal for East European Management Studies, 9(3), 243-264. Retrieved from https://www.jstor.org/stable/23280829? seq=1

Remuzzi A. \& Remuzzi, G. (2020). COVID-19 and Italy: What's next? Health Policy, 395, 1225-1228. https://doi.org/10.1016/S0140-6736(20)30627-9

Rickles, D., Hawe, P., \& Shiell, A. (2007). A simple guide to chaos and complexity. Journal of Epidemiology and Community Health, 61(11), 933-937. https://doi.org/10.1136/jech.2006.054254

Sanger, M., \& Giddings, M. M. (2012). A simple approach to complexity theory. Journal of Social Work Education, 48(2), 369-376. https://doi.org/10.2307/41705869

Schneider, M., \& Somers, M. (2006). Organizations as complex adaptive systems: Implications of complexity theory for leadership research. The Leadership Quarterly, 17(4), 251-265. https://doi.org/10.1016/j.leaqua.2006.04.006 
Smith, S., \& Paquette, S. (2010). Creativity, chaos and knowledge management. Business Information Review, 27(2), 118-123. https://doi.org/10.1177/0266382110366956

Stonebraker, P. W., \& Afifi, R. (2004). Toward a contingency theory of supply chains. Management Decision, 42(9), 1131-1144. https://doi.org/10.1108/00251740410565163

Swanson, L. A., \& Zhang, D. D. (2011). Complexity theory and the social entrepreneurship zone. Emergence: Complexity \& Organization, 13(3), 39-56. Retrieved from http://library.capella.edu/login?url= http://search.ebscohost.com/login.aspx?direct=true\&db=bth\&AN=70109946\&site=ehost-live\&scope=site

Teisman, G. R., \& Klijn, E.-H. (2008). Complexity theory and public management. Public Management Review, 10(3), 287-297. https://doi.org/10.1080/14719030802002451.

Tenhiälä, A. (2011). Contingency theory of capacity planning: The link between process types and planning methods. Journal of Operations Management, 29(1-2), 65-77. https://doi.org/10.1016/j.jom.2010.05.003

Thietart, R. A., \& Forgues, B. (1995). Chaos theory and organization. Organization Science, 6(1), 19-31. https://doi.org/10.1287/orsc.6.1.19

Thompson, J. D. (2003). Organizations in action: Social science bases of administrative theory. Piscataway, NJ: Transaction Publishers.

Tosi, H. L., \& Slocum, J. W. (1984). Contingency theory: Some suggested directions. Journal of Management, 10(1), 9-26. https://doi.org/10.1177/014920638401000103

Uhl-Bien, M., Marion, R., \& McKelvey, B. (2007). Complexity Leadership Theory: Shifting leadership from the industrial age to the knowledge era. 18(4), 298-318. https://doi.org/10.1016/j.leaqua.2007.04.002

Warren, K., Franklin, C., \& Streeter, C. L. (1998). New directions in systems theory: Chaos and complexity. Social Work, 43(4), 357-372. https://doi.org/10.1093/sw/43.4.357

Wilson, M. (2009). Complexity theory. Whitireia Nursing Journal, 16, 18-24. Retrieved from http://library.capella.edu/login?url=http://search.ebscohost.com/login.aspx?direct=true\&db=ccm\&AN=2010510 $181 \&$ site $=$ ehost-live \&scope $=$ site

Zeithaml, V. A., Varadarajan, P. R., \& Zeithaml, C. P. (1967). The contingency approach: Its foundations and relevance to theory building and research in marketing. European Journal of Marketing, 22(7), 37-64. https://doi.org/10.1108/EUM0000000005291 